Review

\title{
A Narrative Review of Virtual Reality Applications for the Treatment of Post-Traumatic Stress Disorder
}

\author{
Sorelle Audrey Kamkuimo ${ }^{1, * \mathbb{D}}$, Benoît Girard ${ }^{2}$ and Bob-Antoine J. Menelas ${ }^{1, * \mathbb{D}}$ \\ 1 Department of Computer Sciences and Mathematics, University of Quebec at Chicoutimi, 555 Blv Universite, \\ Chicoutimi, QC G7H 2B1, Canada \\ 2 La Futaie, Therapy Center, 1061, Boulevard Tadoussac, Saint-Fulgence, QC G0V 1S0, Canada; \\ beni.girard@gmail.com \\ * Correspondence: sorelle-audrey.kamkuimo-kengne1@uqac.ca (S.A.K.); bamenela@uqac.ca (B.-A.J.M.)
}

check for updates

Citation: Kamkuimo, S.A.; Girard, B. Menelas, B.-A.J. A Narrative Review of Virtual Reality Applications for the Treatment of Post-Traumatic Stress Disorder. Appl. Sci. 2021, 11, 6683. https://doi.org/10.3390/app11156683

Academic Editors: Chang-Hun Kim and Soo Kyun Kim

Received: 30 May 2021

Accepted: 16 July 2021

Published: 21 July 2021

Publisher's Note: MDPI stays neutral with regard to jurisdictional claims in published maps and institutional affiliations.

Copyright: (c) 2021 by the authors. Licensee MDPI, Basel, Switzerland. This article is an open access article distributed under the terms and conditions of the Creative Commons Attribution (CC BY) license (https:// creativecommons.org/licenses/by/ $4.0 /)$.

\begin{abstract}
Virtual reality (VR) technologies allow for the creation of 3D environments that can be exploited at the human level, maximizing humans' use of perceptual skills through their sensory channels, and enabling them to actively influence the course of events that take place in the virtual environment (VE). As such, they constitute a significant asset in the treatment of post-traumatic stress disorder (PTSD) via exposure therapy. In this article, we review the VR tools that have been developed to date for the treatment of PTSD. The article aims to analyze how VR technologies can be exploited from a sensorimotor and interactive perspective. The findings from this analysis suggest a significant emphasis on sensory stimulation to the detriment of interaction. Finally, we propose new ideas regarding the more successful integration of sensorimotor activities and interaction into VR exposure therapy for PTSD.
\end{abstract}

Keywords: virtual reality; exposure therapy; VRET; PTSD; learning; interaction; serious games

\section{Introduction}

Virtual reality (VR) technologies have been used in the treatment of post-traumatic stress disorder (PTSD) since the end of the 1990s [1,2]. Such technologies are utilized specifically in exposure therapy [3], whose central principle is to confront patients with the object of anxiety in order to allow them to learn new associations that are contradictory to the dysfunctional beliefs instilled in their memory due to the traumatic situation [4]. The primary added value of using VR technologies for exposure therapy lies in the possibility of creating 3D environments that are representative of the patient's trauma environments and usable on a human scale [5,6]. This advantage is perceptible for several reasons. For example, it is possible to conceptualize various therapy scenarios that would, in reality, be concretely undesirable, such as wars, plane accidents, and explosions $[7,8]$. The therapist, meanwhile, has control over the simulation and can adapt or repeat it multiple times depending on the narration and/or the emotional state of the patient [6]. The use of stimuli directed toward different sensory channels improves the patient's immersion in the virtual environment (VE) and, it is hoped, can help evoke the feeling of being present in that world $[9,10]$. This feeling of presence in the virtual world should promote the patient's emotional engagement in therapy and should, therefore, facilitate access to the fear-inducing memory for the assimilation of corrective information $[7,11,12]$.

The VE is a priori safe and offers various contexts and activities for therapy without extra costs [11,12]; this can be a considerable asset for the patient's involvement in treatment [13]. The naturalness of interactions, if they are highlighted and adapted to the VR tool [14], can promote the transfer and, in turn, the generalization of skills learned during therapy in the context of the patient's life in the future [15]. Patients can also evaluate their progress more directly throughout the treatment while being observed by the therapist [13]. Moreover, this type of therapy can be practised privately and confidentially for 
those patients who prefer the discretion they are denied when exposed to real-life settings. Another benefit of such technologies in virtual reality exposure therapy (VRET) could be the integration, in real time, of a virtual therapist in order to extend into the virtual world the concept of personal care in therapy [16].

It should be noted that the essence of VR technologies lies in the possibility of allowing the user to experience an alternative reality [17-20]. Researchers have elucidated three main elements that characterize these technologies: immersion, presence, and interaction [21-26]. The notion of immersion is closely linked to technological devices used to envelop the user and to enable interaction with an environment that provides a continuous flow of stimuli [26]. Immersion has the potential to engage the user in the experience via a stimuli flow aimed at capturing the user's attention [25]. However, this immersion cannot control the user's mind. This point is attributed to the element of presence: "How the user subjectively experiences the immersion is known as presence" [26]. Presence, therefore, is the feeling of "being there" in the VE, despite being physically in the real world [21]. The experience of presence implies for the user the possibility of having control over the VE through interactions, i.e., the extent to which the user actively participates in modifying the content of the VE in real time [27].

In this article, we review VR tools that have been proposed for the treatment of PTSD and analyze how the three key concepts of VR above are applied. From this analysis, we have observed a lack of means of interaction for the patient; most of the tools seem to focus instead on sensory stimulation. Nevertheless, because exposure therapy works primarily through a learning mechanism [28], and successful and sustainable learning is intended to be active $[29,30]$, we will propose several new ideas to better consider immersion, presence, and interaction in VRET for PTSD through sensorimotor activities.

\section{Analysis of VRET Tools Used for the PTSD Treatment}

In this section, we examine the VR tools that have been developed to treat patients with PTSD. We are particularly interested in the sensorimotor possibilities and interactions integrated into each device, as well as how they are exploited in therapy. These parameters constitute the inclusion criteria for our review. The identification of studies to be considered was made in accordance with the work identified by other recognized reviews in the field [31-33]. For each study, we read the full text; the definitively accepted work had to clearly describe the VE, the central interfaces used, and the sensorimotor possibilities offered to the user. Our review identified 10 VR tools that have been used to simulate various traumatic situations, including war, terrorist attacks, violent assaults, and motor vehicle accidents. The VRET procedure using these tools consisted of 4 to 20 sessions of 45 to $120 \mathrm{~min}$. During the treatment, patients are predominately passive, narrating their trauma while visually exploring the VE, generally through an HMD. Some devices allow patients to explore by moving around using a gamepad. Meanwhile, through a control panel, the therapist adapts the VE according to the patient's description of the traumatic event [6,34]. This adaptation consists of manipulating anxiety-provoking stimuli, which may be visual, auditory, olfactory, or tactile [7,35]. The aim is to effectively trigger stressful reactions from the patient in order to access the fear memory [3].

\subsection{Virtual Vietnam System}

VR technologies were first used to treat PTSD in the late 1990s. Based on the positive results of treating acrophobia with VRET, Rothbaum et al. hypothesized that prolonged exposure to trauma in a safe VE would significantly reduce PTSD symptoms [1]. Thus, they created the "Virtual Vietnam" system to treat Vietnam War veterans with chronic PTSD [1]. This system immersed the patients in a 3D world with content that simulated two situations prevalent in the Vietnam War: a jungle clearing and a helicopter. These two environments presented the user with visual stimuli such as fog and flying or landing helicopters accompanied by auditory stimuli, including sounds of the jungle, firearms, and helicopters. In the virtual helicopter environment, the subject could see the interior of 
the aircraft as well as shots of other flying helicopters, the jungle, and a river through the helicopter's side door. These VEs could be explored using an HMD supporting both visual and auditory renderings of the 3D scene presented to the user. To improve the patients' immersion, the authors added vibrotactile stimuli using a woofer attached to the patient's seat to simulate the helicopter's vibrations according to the scene presented in the 3D VE. The sound transmitted through the headphones was similarly intended to match the scene shown on the screens, while the armchair vibrations corresponded to the shaking of the VE. The scenario was designed to be manually updated by the therapist according to the patient's narration during the sessions.

Several studies involving a total of 33 Vietnam War soldiers or veterans have reported using the Virtual Vietnam tool for the treatment of PTSD [1,36-38]. Overall, there was a 15-67\% reduction in PTSD symptoms after the treatment. These results were maintained at the 3-month and 6-month follow-ups. However, one study indicated a substantial increase in anxiety levels in two patients after treatment [36].

\subsection{Virtual Iraq System}

The "Virtual Iraq" system is described in a study by Rizzo et al. [35]. Researchers reused assets from the Xbox game Full Spectrum Warrior to create a VRET scenario for Iraq War veterans with PTSD. This VE presented several possible scenes related to cities, villages, and deserts in the Middle East. The user could navigate these scenarios from several perspectives, such as walking alone, on patrol, or in a war vehicle using a gamepad. An interface was integrated to allow the therapist to tailor the therapy according to each patient's specific needs, modulating the anxiety levels of stimuli and controlling the patient's physiological state during treatment. Four main types of stimuli were included: (1) auditory (e.g., weapons fire, explosions, vehicle noises, wind, human voices); (2) static visual (e.g., human remains, wounded civilians and combatants, wrecked vehicles); (3) dynamic visual (e.g., distant views of human and vehicular movement); and (4) dynamic audiovisual (e.g., nearby human and vehicular movement, battlefield engagements with enemy combatants). Much like the Virtual Vietnam tool, this VE incorporated visual, auditory, olfactory, and vibrotactile stimuli rendered in parallel to the subject during exposure. The scenes were displayed on an HMD with a tracking system with three degrees of freedom. The olfactory stimuli were generated by a scent palette capable of distilling several different smells, including burning rubber, cordite, garbage, body odour, smoke, diesel fuel, Iraqi spices, and gunpowder, which were chosen according to the given scene of exposure. The vibrotactile stimuli were added with a sound transducer, which converted the audio signal into vibrations.

Several clinical studies have utilized this system to treat active-duty soldiers and veterans of the Iraq and Afghanistan Wars living with PTSD [39-50]. A total of 58 patients were involved in these studies. Overall, the results suggest a $22-65 \%$ improvement in all patients. In most cases, treatment results were maintained with 3- and 6-month follow-ups after therapy. While the results did not appear to be very satisfactory in the first half of treatment in some studies, patients showed improvement at the end of treatment [47]. In addition, scholars have highlighted several cases of abandonment in the treatment $[40,45]$. There was also a case where the treatment did not produce satisfactory therapeutic results [45]. It should be noted that some studies combined VRET with real-life exposure $[41,46]$ to eliminate the boredom perceived by the patient during VRET sessions [46] or to allow the patient to apply the skills acquired during VRET to their real lives [50].

\subsection{BRAVEMIND System}

BRAVEMIND (Battlefield Research Accelerating Virtual Environments for Military Individual Neuro Disorders) [6] can be regarded as the updated version of the Virtual Iraq system. This tool encompasses four subsystems: a BRAVEMIND Virtual Iraq/Afghanistan system for combat-related PTSD; an expansion for combat medics and corpsmen; an expansion known as BRAVEMIND-MST for military sexual trauma; and an expansion for 
the assessment of PTSD. The primary improvements to the previous system entailed the redesign of previous scenarios, the addition of 10 new ones, and more capabilities for the clinician to control the VE via a "Wizard of Oz" control panel. As in the earlier Virtual Iraq tool, the user could move around the VE using a gamepad and visually explore a 360-degree landscape using a head-mounted display. In the expansion for medics and corpsmen, development efforts have focused on visual realism in terms of graphics and animations of injured characters. The last subsystem, BRAVEMIND-MST, is described more fully below.

\subsection{BRAVEMIND-MST System}

In 2020, Mozgai et al. reported their work on the BRAVEMIND-MST subsystem [34]. They focused on the development of three aspects: VR environments, user-avatar states, and events. The system exploited one of the environments of the BRAVEMIND Virtual Iraq/Afghanistan system but included an additional environment representing a small town in the United States featuring a bar exterior, alleyway, empty lot, strip mall, motel exterior, motel bedroom/bathroom, apartment, office, women's/men's bathrooms, and a car ride. Meaningful configurations were made to lights to better represent the moods of sexual assault (i.e., at night or in dark places during the day). The user-avatar states refer to the user's position and orientation within the VE during exposure. The BRAVEMIND-MST subsystem re-exploits the users' perspectives of the previous systems (e.g., walking and sitting in the vehicle) and adds a new perspective, "lying down." For combat-related PTSD, meanwhile, exploited events refer to the triggering of stimuli by the clinician through a separate "Wizard of $\mathrm{Oz}$ " control panel. These events include breathing, TV, showering, doors opening and closing, and the presence of an aggressor.

To our knowledge, subsequent research has not yet focused on the use of this system.

\subsection{Virtual World Trade Center (WTC) System}

Difede and Hoffman developed the "Virtual WTC" tool to treat PTSD in victims of the WTC terrorist attack on 11 September 2001 [7]. This tool included eleven anxiety-provoking scenes that could be gradually integrated by the therapist during treatment. Exposure began in a VE presenting a simple jet flight, followed by overflights of the towers. These scenes were accompanied by an explosion and crash and ultimately led to the towers' collapse with corresponding visual and auditory effects. The auditory stimuli were based on recordings from that day's national newspapers. The patient could explore all stimuli via an HMD.

An initial study using the Virtual WTC system was conducted with a 26-year-old woman who witnessed the WTC attack and presented symptoms of acute PTSD and major depression [7]. At the end of treatment, the patient no longer had the diagnostic criteria for PTSD, major depression, or any other psychiatric disorder. Another use of the Virtual WTC system was administered to treat a 49-year-old firefighter who had symptoms of PTSD after the WTC attack [43]. Over the course of the treatment, the patient showed noticeable improvements in both their family and professional lives. Finally, the patient no longer presented a significant emotional response to stimuli. He ended up accepting the situation and decided to focus on the future.

\subsection{VR System for Treating Victims of African Wars}

Gamito et al. developed a VR ambush scenario to reduce symptoms of PTSD in veterans of African wars that took place between 1961 and 1974 [51]. This tool used a translucent screen and a projector to expose the patient to a VE, accompanied by environmental sounds corresponding to the scene presented on the visual device. Bass shakers were also used to add vibration to the patient's seat. The VE comprised two paths surrounded by vegetation and a column of virtual soldiers that the patient had to follow. During the exposure, visual, auditory, and vibrotactile stimuli were rendered in a coordinated and gradual manner. 
These stimuli included the sounds of gunshots, tracer bullets and dynamite, black smoke, particles resulting from explosions, and sounds associated with evacuating injured soldiers.

The authors carried out a pre-experimental case study to evaluate the effectiveness of this tool in reducing the symptoms of PTSD in a 60-year-old African war veteran who met the diagnostic criteria for PTSD [51]. The critical element of this therapy was the patient's gradual confrontation with intense fear. Unfortunately, however, the patient abandoned the treatment after seven sessions due to continuous flashbacks and nightmares.

\subsection{BusWorld System}

Josman et al. created the BusWorld tool to treat survivors of a suicide bombing bus attack presenting with PTSD symptoms [8]. This tool incorporated visual and auditory stimuli shown to the patient via an HMD during the treatment. The environment was designed to allow the therapist to expose the patient to traumatic situations in a gradual and controllable manner. Four levels of VEs featuring anxiety-provoking stimuli were presented: (1) a quiet street scene in Israel; (2) a bus approaching the bus stop without exploding; (3) the explosion of the bus at the bus stop; and (4) the explosion sequence with added sounds (e.g., explosions, screaming people, and police sirens).

Using the BusWorld tool, the authors conducted a case study consisting of VR-assisted imaginary exposure therapy with a 29 -year-old Israeli citizen. The patient was living with PTSD and depression following a bulldozer terrorist attack [52]. The post-treatment and 6-month follow-up reports indicate that the patient ultimately recovered.

\subsection{VR System for Treating Victims of Violent Assault}

Cárdenas-López and De la Rosa-Gómez developed a VR system to treat PTSD in victims of violent assault [53]. The VE presented three scenes of exposure: (1) the streets of Mexico (a public place in which the patient could move and that contained suspiciouslooking avatars that could be placed close to the patient); (2) a pedestrian bridge to which avatars could be added and that the patient had to cross; and (3) a vehicle (taxi or wagon) in which the patient was confronted by an intimidating driver and other frightening situations (e.g., threatening avatars, a blocked path, or changes in brightness). Devices used in this system included an HMD, headphones, speakers, and a computer displaying the VE.

An initial case study with this tool was carried out with a 22-year-old participant presenting the diagnostic criteria for PTSD after a violent assault with death threats [54]. The results showed a 51\% reduction in PTSD symptoms. Another study involved 10 participants who met the diagnostic criteria for PTSD after having experienced or witnessed criminal violence, assault, or kidnapping. At the end of treatment, there was a $75 \%$ decrease in the average of the participants' PTSD symptoms.

\subsection{VR System for Treating Victims of Motor Vehicle Accidents}

One of the first studies using VR to treat PTSD related to motor vehicle accidents was conducted in 2007 [55]. The VEs used in this study consisted of roads that resembled those that patients used to see in real life, with four types of scenes available: highway, urban, suburban, and rural. The patient viewed these scenes through stereoscopic glasses. Depending on the specific exposure situation, the patient could experience each session as a passenger or a driver, with the therapist taking the other role. The device comprised a movement base with six degrees of freedom, equipped with a steering wheel, an accelerator pedal, and a brake pedal. Visual, auditory, and tactile stimuli were used to alter the anxiety levels of the rendered scene. During the sessions, the therapist was able to modify several parameters, including the density and the type of traffic, the time of day, weather conditions, and specific driving events.

This tool was tested with six patients who had PTSD following motor vehicle accidents [55]. The authors reported an average reduction in PTSD symptoms of around $43 \%$ at the end of the treatment. It must nonetheless be noted that while eight patients had been recruited, two dropped out before the fifth session. 
Haidon et al. [12], Ecrepont et al. [56] and, later, Menelas et al. [15] instituted a VR truck-driving simulator and proposed a new way of approaching VRET. They argued that the traditional methods of exposure therapy treatment emphasize the patient's exposure to frightening stimuli without allowing the patient to act. Consequently, in their simulator, they prioritized the patient's behaviour when faced with anxiety-provoking stimuli. They also highlighted the necessity of creating a VE that not only provides stimuli adapted to the patient's mental state but also allows the patient to be active. These aims were achieved through gamification and personalization of the truck-driving simulator. The gamification process was enforced by linking game mechanics to learning mechanics while basing the VE on the main characteristics of a serious game (SG). The personalization process was intended to create, for each patient, a VE similar to that of the patient's traumatic environment that was capable of prompting emotions and offering flexible scenarios. An environment editor that was easily customizable by the therapist was also incorporated. Aspects that could be adapted to a particular patient's circumstances included the characteristics of the roads and the truck as well as weather conditions. Several devices were used for the exposure, including an HMD to facilitate visual exploration of the scene; for driving, a system consisting of a steering wheel, a gearbox, and pedals was used. This device allowed users to move the truck as they would in reality and offered other basic features such as light, sounds, and wipers.

This system was used in a case study to treat a truck driver with PTSD following a traffic accident [15]. The patient had previously received another form of therapy without success and was taking medication. The treatment involved placing the patient-and the patient's actions-at the centre of the process. The authors were concerned with developing a tool that enabled the patient to engage with the VE through precise interaction mechanics, such as choosing a truck, driving the truck, and turning on the radio and the windshield wipers. At the end of the treatment, the patient regained control over his life and decided to undertake professional retraining. The authors highlighted the engagement and motivation observed in the patient at each stage of therapy.

Table 1 summarises the reviewed tools listed from the lowest to highest amount of sensorimotor input.

\subsection{Studies Comparing VRET to Other Conditions}

Most of the studies comparing VRET to traditional exposure and other treatment conditions have highlighted the inadequacies of the latter and championed the former, leading to a necessary reconsideration of how VRET for PTSD is approached [57-61]. Nevertheless, although in one case, VRET was found to be superior to traditional exposure [62], other studies have demonstrated no significant differences in results between VRET and standard exposure therapy $[60,63,64]$. Furthermore, two comparative studies reported the superiority of traditional exposure over VRET $[59,65]$. It is also crucial to note that in these comparative studies, abandonment cases were more visible in the VRET groups than in traditional exposure therapy $[61,65]$. 
Table 1. Summary of the review of virtual reality tools exploited in the treatment of post-traumatic stress disorder.

\begin{tabular}{|c|c|c|c|c|}
\hline Paper & VR System & Technological Devices Used & Sensorial Input & Motor Activity \\
\hline [7] & Virtual World Trade Center & - $\quad$ An HMD for visual exploration & $\begin{array}{ll}\text { - } & \text { Visual } \\
\text { - } & \text { Auditory }\end{array}$ & - $\quad$ Not specified \\
\hline [8] & BusWorld & - $\quad$ An HMD for visual exploration & $\begin{array}{ll}- & \text { Visual } \\
- & \text { Auditory }\end{array}$ & - $\quad$ Not specified \\
\hline [53] & $\begin{array}{l}\text { VR system for treating victims of violent } \\
\text { assault }\end{array}$ & $\begin{array}{l}\text { - } \quad \text { HMD for visual exploration } \\
\text { - } \quad \text { from the virtual world } \\
\text { - Computer displaying virtual environment }\end{array}$ & $\begin{array}{ll}- & \text { Visual } \\
- & \text { Auditory }\end{array}$ & $\begin{array}{l}\text { - } \\
\text { savigation (device not } \\
\text { specified) }\end{array}$ \\
\hline [1] & Virtual Vietnam & $\begin{array}{ll}- & \text { An HMD for visual exploration } \\
- & \text { A woofer to simulate vibrations } \\
\text { - } & \text { Headphones } \\
\text { - } & \text { A joystick to navigate }\end{array}$ & $\begin{array}{ll}- & \text { Visual } \\
\text { - } & \text { Auditory } \\
\text { - } & \text { Tactile }\end{array}$ & - $\quad$ Navigation with a joystick \\
\hline [35] & Virtual Iraq & $\begin{array}{ll}\text { - } & \text { A gamepad to navigate } \\
\text { - } & \text { An HMD for visual exploration } \\
\text { - } & \text { A scent palette to distill smells } \\
\text { Sound transducer to simulate vibrations }\end{array}$ & $\begin{array}{ll}\text { - } & \text { Visual } \\
\text { - } & \text { Auditory } \\
\text { - } & \text { Tactile } \\
\text { Olfactory }\end{array}$ & - Navigation with a gamepad \\
\hline [6] & BRAVEMIND & $\begin{array}{ll}\text { - } & \text { A gamepad to navigate } \\
\text { - } & \text { An HMD for visual exploration } \\
\text { - } & \text { A scent palette to distill smells } \\
\text { Sound transducer to simulate vibrations }\end{array}$ & $\begin{array}{ll}- & \text { Visual } \\
- & \text { Auditory } \\
\text { - } & \text { Tactile } \\
\text { - } & \text { Olfactory }\end{array}$ & - $\quad$ Navigation with a gamepad \\
\hline [34] & BRAVEMIND-MST & - The same as in BRAVEMIND & - $\quad$ The same as in BRAVEMIND & - $\quad$ The same as in BRAVEMIND \\
\hline
\end{tabular}


Table 1. Cont.

\begin{tabular}{|c|c|c|c|c|}
\hline Paper & VR System & Technological Devices Used & Sensorial Input & Motor Activity \\
\hline [55] & $\begin{array}{l}\text { VR system for treating victims of motor } \\
\text { vehicle accidents }\end{array}$ & $\begin{array}{l}\text { - Stereoscopic glasses for visual exploration } \\
\text { A movement base with six degrees of freedom, } \\
\text { equipped with a steering wheel, an accelerator } \\
\text { pedal, and a brake pedal }\end{array}$ & $\begin{array}{ll}- & \text { Visual } \\
- & \text { Tactile } \\
\text { - } & \text { Haptic } \\
\text { - } & \text { Motor }\end{array}$ & - $\quad$ Driving \\
\hline [12] & VR truck driving simulator & $\begin{array}{l}\text { - } \quad \text { HMD for visual exploration } \\
\text { A driving device containing the steering wheel, } \\
\text { gearbox, and pedals }\end{array}$ & $\begin{array}{ll}- & \text { Visual } \\
- & \text { Auditory } \\
- & \text { Haptic } \\
- & \text { Motor }\end{array}$ & - $\quad$ Driving \\
\hline
\end{tabular}




\section{Discussion}

In line with other researchers who have been interested in the use of VRET for the treatment of PTSD, we believe that VR has immense potential to succeed in this area. If, however, it is not exploited for the benefits it offers, it may not be appreciated for its true value. Given the cases of abandonment, the lack of significant reductions in PTSD symptoms, and the increase in these symptoms in some patients as observed in the previous review, it is essential to identify the main components that would ensure that VR merges effectively with learning, which is the primary mechanism behind the effectiveness of exposure $[28,66]$. We will elaborate on this concern by discussing two observations made from the previous analysis.

\subsection{Emphasis on Sensory Stimulation without Interactions}

Many tools discussed in this review have emphasized only certain characteristics of immersion and presence through sensory stimulation while neglecting to offer means of interaction to the subject. Indeed, in addition to the visual devices used, such as immersive headsets, we note the use of various other technological devices to reproduce the realistic ambience of the events occurring in the VEs involved in the therapy. These devices include headphones to transmit sounds related to the VE, scent palettes to distill scents dependently of events in the virtual world, and devices that simulate vibrations of the patient's seat $[6,34,35,53]$. Thus, patients are immersed in an environment that they can visually explore and, in some cases, navigate while the VE is manually updated by the therapist. This emphasis on sensory immersion and stimulation is largely due to the inclination of current approaches to VRET to consider the therapy as "similar to traditional PE (Prolonged Exposure), with the largest difference being that aspects of the trauma are illustrated for the patient within a VR (Virtual Reality) simulator while the patient narrates the trauma experience" [50]. Scholars have argued that interactions constitute an essential element of VR. According to Sherman and Craig, for example: "VR is a medium composed of interactive computer simulations that sense the participant's position and actions and replace or augment feedback to one or more senses, giving the feeling of being mentally immersed or present in the simulation (a virtual world)" [18]. Nonetheless, interactions are presently lacking in VRET.

\subsection{Supporting the Active Experience of Users Is Necessary}

Some of the researchers discussed in this review have taken the initiative to implement VR tools among people who do not present symptoms of PTSD, in order to assess their quality and ability to generate anxiety [8,67]. For example, after active-duty soldiers in Iraq without PTSD tried the Virtual Iraq tool, they raised criticisms regarding the lack of realism [67]. In response, the authors added more avatars and vehicles to the environment. However, we believe that this level of realism could also be enhanced by developing components that would increase the subjects' levels of control through their interactions with the VE.

Moreover, researchers have conceptualized contributing factors of presence in VE, categorizing them into four groups [26]: control factors, sensory factors, distraction factors, and realism factors. Control factors describe the mastery that the subject must have over the VE. Sensory factors relate to how information is presented through several sensory modalities and how the subject perceives that information. Distraction factors refer to interface awareness and the extent to which the user is isolated from the real world. Finally, realism factors are related to the naturalism of the VE and the relevance of the user experience. These categories align with those established by Riva et al. [21] and Sheridan [68], which highlighted sensory information, user control, and VE modifiability as essential for presence. This suggests, therefore, that if the subject interacts with the system using the same mechanics as those present in real life, they will likely experience a strong feeling of both perceived realism and presence in the exposure environment [13]. 
In other tests using the Virtual Iraq tool, participants suggested that patients should be allowed a gun, which they would be able to fire if necessary [67]. From this, we can infer that the subjects might have a deep desire to interact with the VE-either to defend themselves or to relive the traumatic situation differently-and that it may be worth enabling patients to rectify errors they believe they committed during the actual traumatic event. This last possibility would be particularly interesting to explore for patients who have strong feelings of guilt connected to their traumas.

Another point that we can garner from this review is the level of perceived boredom in VRET, as highlighted in [46]. In this study, the authors stated that the patient experienced boredom during the in virtuo treatment and was subjected to in vivo experiences to resolve this boredom. We can, of course, partially reproduce a traumatic situation in real life for some cases of PTSD; nevertheless, this cannot be possible for all cases because of the myriad factors involved, including the nature of the situation and the anxiety level of the patient. Thus, if it is impossible to reproduce the scenario in vivo, one can only base the treatment and its results on in virtuo sessions. As such, effective parameters for the design of VEs that favour adhesion and patient engagement, as well as allowing patients to invest in the VE as if it were reality, must be considered.

Finally, although many existing VRET studies for PTSD have not focused on the interaction between subject and environment, some of them have reported behaviours reflecting the need for action that a patient may have in VRET situations [51]. A striking example was noted in a case study by Gamito et al. involving victims of African wars [51]: "where cue intensity was raised, the participant assumed a combat position (arms and hands in a position such as if a firearm was being carried), trying to find the enemy within the scenario. When triggers such as ambush and mine deflagration occurred, the patient tried to take cover and started simulating firing. The subject maintained this behaviour pattern throughout the following sessions." The positive point that we can highlight regarding this behaviour would be the degree of presence felt by the subject in the VE. However, we posit that this behaviour could also exhibit the need for natural interactions that the user would like to have with the VE. The depth of this behaviour may also suggest that the patient might prefer to relive the traumatic scene differently through self-defence. The subject may, therefore, perceive their self-efficacy and try to overcome their fears through actions [13]. This assumption is in line with work on certain specific phobias, such as the fear of spiders, for which perceived self-efficacy is a good indicator of improvement [69].

\section{How Could Interactions in VRET Be Improved?}

Unlike existing studies, which seem to consider VR a simple medium to help patients narrate their trauma in an imaginary scenario of exposure therapy [3,50], we argue that VRET should be regarded as a full-fledged therapy because VR technologies can effectively enable the application of so-called active methods of learning. Indeed, it has been established that exposure therapy operates through a learning mechanism $[28,66]$. Learning has evolved through several models, and current assumptions are that better learning results from a subject's active participation in the process. During an active learning experience, subjects are engaged in activities that involve concrete encounters. They think about what they learn, relate it to their past experiences, and apply their learning to their daily lives [70,71]. They must have a sense of progress and control over their learning [70], in accordance with the principles of VR, which suggest a continual loop of the user's actions and the environment's feedback [18]. However, findings indicate that notwithstanding the potential of VR to allow the subject to be actively involved during VRET, the exposure remains a passive learning process for the patient. Therefore, we propose two main foundations to consider when designing VEs for VRET:

(1) Learning as the primary mechanism of VRET

(2) The application of key concepts of VR (immersion, presence, and interaction) in VRET 
These foundations could lead to the possibility of considering the therapy process as an SG because this type of game facilitates the effective application of a learner-centred model of learning [72]. SGs consist of activities that allow users to learn while having fun [73-76]. They are characterized by a utilitarian purpose, compounded by a playful purpose through the process of gamification [77]. From the perspective of an SG, we understand that a VRET tool can be regarded as an environment in which the patient seeks to achieve a given objective by means of game mechanics (that is, rules that define what is achievable or not at a specific moment). In this way, the player/patient is required to perform various actions that capture their attention. Thus, the player's engagement in the game is emphasized. As such, by being combined with VR technologies, SGs constitute an effective and natural way for learners to achieve a high level of interaction with the system [72].

One could even push the issue further by considering the VR application as an SG that adapts to the patient during the exposure. Indeed, SG players have game goals that can be achieved by solving one or more challenges in specific contexts. Because all users of the same SG have different learning skills, they may feel bored or frustrated with a game depending on whether it is too easy or too difficult for them. It appears that, for each player, a better balance between one's performances and learning activities would lead to a better transfer of skills, determined by the technique of dynamic difficulty adjustment (DDA) in games. DDA techniques are commonly based on a player's in-game performances. However, several studies have investigated the possibility of an adjustment according to the more objective characteristics of each player, including physiological measures [78-81]. If applied to SGs intended to treat mental disorders, such methods would yield compelling results because physiological parameters are good indicators for the evaluation of a patient's emotional state [49]. Physiological reactions involved in stress responses associated with PTSD include the reactivity of the heart rate [82]. These responses to anxiety-provoking stimuli encapsulate the symptoms of PTSD in hyper-arousal and "reliving" (intrusions, flashbacks, etc.) [83]. Such responses arise from the activation of the subject's fear network when they are confronted with stimuli reminiscent of their trauma and result in an increased heart rate [83]. Thus, during the treatment, the patient's heart rate is generally evaluated at equal time intervals over the sessions, and conclusions are made in accordance with the attenuation or not of cardiac reactivity in the presence of the same anxiety-provoking situation $[9,10,38,49,84]$. With this in mind, then, it would be interesting to design a VRET tool as an SG that incorporates a DDA system allowing the simulation to adapt to the patient's emotional state as defined by the heart rate retrieved in real time. Initial developments of such an approach to therapy were carried out in our recent works $[13,85]$.

\section{Conclusions}

Due to the potential they offer to create an alternative reality, VR technologies remain a tool of choice for treating PTSD, as much in terms of scenario flexibility and parameterization as in terms of efficiency. From our analysis of the VRET applications for PTSD developed to date, we have found that the two key ingredients of VR that tend to be only partially considered are immersion and presence. However, from the primary definitions of VR technologies, their particularity lies in the possibility of transporting the user to a full-scale artificial world, allowing them to experience a new reality by interacting with that world $[17,18,20]$. This could be a good asset for promoting the active model of learning in VRET because learning is the primary mechanism of exposure therapy. We have proposed new ideas that could allow this enforcement in VR applications for the treatment of PTSD. Such practices would involve designing the VRET tool as an SG capable of being dynamically adjusted in real time to the patient's emotional state. Consequently, in addition to the effective application of the key concepts that characterize VR (immersion, presence, and interaction), the benefits of such an approach could lie in the fact that patients will have 
self-control over the events in the virtual world and the ability to self-regulate their anxiety levels while perceiving their self-efficacy.

Author Contributions: Under the supervision of B.-A.J.M. and B.G., S.A.K. was in charge of planning the review and writing the article. All authors have read and agreed to the published version of the manuscript.

Funding: This research was funded by the Natural Sciences and Engineering Research Council of Canada (NSERC); grant number from NSERC is RGPIN-2019-07169.

Institutional Review Board Statement: Not applicable.

Informed Consent Statement: Not applicable.

Data Availability Statement: Not applicable.

Conflicts of Interest: The authors declare no conflict of interest.

\section{References}

1. Rothbaum, B.O.; Hodges, L.; Alarcon, R.; Ready, D.; Shahar, F.; Graap, K.; Pair, J.; Hebert, P.; Gotz, D.; Wills, B. Virtual reality exposure therapy for PTSD Vietnam veterans: A case study. J. Trauma. Stress Off. Publ. Int. Soc. Trauma. Stress Stud. 1999, 12, 263-271. [CrossRef] [PubMed]

2. Rothbaum, B.O.; Hodges, L.; Watson, B.A.; Kessler, G.D.; Opdyke, D. Virtual reality exposure therapy in the treatment of fear of flying: A case report. Behav. Res. Ther. 1996, 34, 477-481. [CrossRef]

3. Sherrill, A.M.; Rothbaum, A.O.; McSweeney, L.B.; Rothbaum, B.O. Virtual Reality Exposure Therapy for Posttraumatic Stress Disorder. Psychiatr. Ann. 2019, 49, 343-347. [CrossRef]

4. Foa, E.; Hembree, E.; Rothbaum, B.O. Prolonged Exposure Therapy for PTSD: Emotional Processing of Traumatic Experiences Therapist Guide; Oxford University Press: Oxford, UK, 2007.

5. Bouchard, S.; Côté, S.; Richard, D.C. Virtual reality applications for exposure. In Handbook of Exposure Therapies; Elsevier: Cambridge, MA, USA, 2007; pp. 347-388.

6. Rizzo, A.; Roy, M.J.; Hartholt, A.; Costanzo, M.; Highland, K.B.; Jovanovic, T.; Norrholm, S.D.; Reist, C.; Rothbaum, B.; Difede, J. Virtual reality applications for the assessment and treatment of PTSD. In Handbook of Military Psychology; Springer: Cham, Switzerland, 2017; pp. 453-471.

7. Difede, J.; Hoffman, H.G. Virtual reality exposure therapy for World Trade Center post-traumatic stress disorder: A case report. CyberPsychol. Behav. 2002, 5, 529-535. [CrossRef]

8. Josman, N.; Reisberg, A.; Weiss, P.L.; Garcia-Palacios, A.; Hoffman, H.G. BusWorld: An analog pilot test of a virtual environment designed to treat posttraumatic stress disorder originating from a terrorist suicide bomb attack. CyberPsychol. Behav. 2008, 11, 775-777. [CrossRef] [PubMed]

9. Walshe, D.; Lewis, E.; O'Sullivan, K.; Kim, S.I. Virtually driving: Are the driving environments "real enough" for exposure therapy with accident victims? An explorative study. CyberPsychol. Behav. 2005, 8, 532-537. [CrossRef] [PubMed]

10. Walshe, D.G.; Lewis, E.J.; Kim, S.I.; O'Sullivan, K.; Wiederhold, B.K. Exploring the use of computer games and virtual reality in exposure therapy for fear of driving following a motor vehicle accident. CyberPsychol. Behav. 2003, 6, 329-334. [CrossRef] [PubMed]

11. Haidon, C.; Ecrepont, A.; Girard, B.; Menelas, B.-A.J. Gamification of a truck-driving simulator for the care of people suffering from post-traumatic stress disorder. In Proceedings of the International Conference on Games and Learning Alliance, Rome, Italy, 9-11 December 2015; pp. 312-322.

12. Haidon, C.; Ecrepont, A.; Girard, B.; Menelas, B.-A.J. A driving simulator designed for the care of trucker suffering from post-traumatic stress disorder. In Serious Games and Edutainment Applications; Springer: Cham, Switzerland, 2017 ; pp. 411-431.

13. Kamkuimo Kengne, S.A.; Fossaert, M.; Girard, B.; Menelas, B.-A.J. Action-Centered Exposure Therapy (ACET): A new approach to the use of virtual reality to the care of people with post-traumatic stress disorder. Behav. Sci. 2018, 8, 76. [CrossRef]

14. Bowman, D.A.; McMahan, R.P.; Ragan, E.D. Questioning naturalism in 3D user interfaces. Commun. ACM 2012, 55, 78-88. [CrossRef]

15. Menelas, B.A.J.; Haidon, C.; Ecrepont, A.; Girard, B. Use of virtual reality technologies as an Action-Cue Exposure Therapy for truck drivers suffering from Post-Traumatic Stress Disorder. Entertain. Comput. 2018, 24, 1-9. [CrossRef]

16. Dayan, E. Argaman: Rapid deployment virtual reality system for PTSD rehabilitation. In Proceedings of the 2006 International Conference on Information Technology: Research and Education, Tel Aviv, Israel, 17-18 October 2006; pp. 34-38.

17. Burdea, G.C.; Coiffet, P. Virtual Reality Technology; John Wiley \& Sons: Hoboken, NJ, USA, 2003.

18. Sherman, W.R.; Craig, A.B. Understanding Virtual Reality: Interface, Application, and Design; Morgan Kaufmann: Burlington, MA, USA, 2018.

19. Merriam-Webster. Virtual Reality. Available online: https://www.merriam-webster.com/dictionary/virtual\%20reality (accessed on 20 September 2020). 
20. Zheng, J.; Chan, K.; Gibson, I. Virtual reality. IEEE Potentials 1998, 17, 20-23. [CrossRef]

21. Riva, G.; Davide, F.; IJsselsteijn, W.A. Being there: The experience of presence in mediated environments. In Being There: Concepts, Effects and Measurements of User Presence in Synthetic Environments; Riva, G., Davide, F., IJsselsteijn, W.A., Eds.; IOS Press: Amsterdam, The Netherlands, 2003; Volume 5, pp. 3-16.

22. Riva, G.; Waterworth, J.; Murray, D. 1 Extending the Self through the Tools and the Others: A General Framework for Presence and Social Presence in Mediated Interactions. In Interacting with Presence; Sciendo Migration: Varsovie, Poland, $2014 ;$ pp. 9-31.

23. Sheridan, T.B. Interaction, imagination and immersion some research needs. In Proceedings of the ACM Symposium on Virtual Reality Software and Technology, Seoul, Korea, 22-25 October 2000; pp. 1-7.

24. Yang, L.; Huang, J.; Feng, T.; Wang, H.-A.; Dai, G.-Z. Gesture interaction in virtual reality. Virtual Real. Intell. Hardw. 2019, 1, 84-112.

25. Jerald, J. The VR Book: Human-Centered Design for Virtual Reality; Morgan \& Claypool: San Rafael, CA, USA, 2015.

26. Witmer, B.G.; Singer, M.J. Measuring presence in virtual environments: A presence questionnaire. Presence 1998, 7, 225-240. [CrossRef]

27. Steuer, J. Defining virtual reality: Dimensions determining telepresence. J. Commun. 1992, 42, 73-93. [CrossRef]

28. Powers, M.B.; Smits, J.A.; Leyro, T.M.; Otto, M.W. Translational research perspectives on maximizing the effectiveness of exposure therapy. In Handbook of Exposure Therapies; Academic Press: Cambridge, MA, USA, 2007; pp. 109-126.

29. Brown, J.S.; Collins, A.; Duguid, P. Situated cognition and the culture of learning. Educ. Res. 1989, 18, 32-42. [CrossRef]

30. Ertmer, P.A.; Newby, T.J. Behaviorism, cognitivism, constructivism: Comparing critical features from an instructional design perspective. Perform. Improv. Q. 1993, 6, 50-72. [CrossRef]

31. Botella, C.; Serrano, B.; Baños, R.M.; Garcia-Palacios, A. Virtual reality exposure-based therapy for the treatment of post-traumatic stress disorder: A review of its efficacy, the adequacy of the treatment protocol, and its acceptability. Neuropsychiatr. Dis. Treat. 2015, 11, 2533. [CrossRef] [PubMed]

32. Deng, W.; Hu, D.; Xu, S.; Liu, X.; Zhao, J.; Chen, Q.; Liu, J.; Zhang, Z.; Jiang, W.; Ma, L. The efficacy of virtual reality exposure therapy for PTSD symptoms: A systematic review and meta-analysis. J. Affect. Disord. 2019, 257, 698-709. [CrossRef]

33. Gonçalves, R.; Pedrozo, A.L.; Coutinho, E.S.F.; Figueira, I.; Ventura, P. Efficacy of virtual reality exposure therapy in the treatment of PTSD: A systematic review. PLoS ONE 2012, 7, e48469. [CrossRef]

34. Mozgai, S.; Hartholt, A.; Leeds, A.; Rizzo, A.S. Iterative Participatory Design for VRET Domain Transfer: From Combat Exposure to Military Sexual Trauma. In Proceedings of the Extended Abstracts of the 2020 CHI Conference on Human Factors in Computing Systems, Honolulu, HI, USA, 25-30 April 2020; pp. 1-8.

35. Rizzo, A.; Pair, J.; Graap, K.; Manson, B.; McNerney, P.J.; Wiederhold, B.; Wiederhold, M.; Spira, J. A virtual reality exposure therapy application for Iraq War military personnel with post traumatic stress disorder: From training to toy to treatment. NATO Secur. Through Sci. Ser. E Hum. Soc. Dyn. 2006, 6, 235.

36. Ready, D.J.; Pollack, S.; Rothbaum, B.O.; Alarcon, R.D. Virtual reality exposure for veterans with posttraumatic stress disorder. J. Aggress. Maltreatment Trauma 2006, 12, 199-220. [CrossRef]

37. Rothbaum, B.O.; Hodges, L.F.; Ready, D.; Graap, K.; Alarcon, R.D. Virtual reality exposure therapy for Vietnam veterans with posttraumatic stress disorder. J. Clin. Psychiatry 2001, 62, 617-622. [CrossRef]

38. Rothbaum, B.O.; Ruef, A.M.; Litz, B.T.; Han, H.; Hodges, L. Virtual reality exposure therapy of combat-related PTSD: A case study using psychophysiological indicators of outcome. J. Cogn. Psychother. 2003, 17, 163-178. [CrossRef]

39. Gerardi, M.; Rothbaum, B.O.; Ressler, K.; Heekin, M.; Rizzo, A. Virtual reality exposure therapy using a virtual Iraq: Case report. J. Trauma. Stress Off. Publ. Int. Soc. Trauma. Stress Stud. 2008, 21, 209-213. [CrossRef] [PubMed]

40. McLay, R.N.; Graap, K.; Spira, J.; Perlman, K.; Johnston, S.; Rothbaum, B.O.; Difede, J.; Deal, W.; Oliver, D.; Baird, A. Development and testing of virtual reality exposure therapy for post-traumatic stress disorder in active duty service members who served in Iraq and Afghanistan. Mil. Med. 2012, 177, 635-642. [CrossRef] [PubMed]

41. Reger, G.M.; Gahm, G.A. Virtual reality exposure therapy for active duty soldiers. J. Clin. Psychol. 2008, 64, 940-946. [CrossRef]

42. Reger, G.M.; Holloway, K.M.; Candy, C.; Rothbaum, B.O.; Difede, J.; Rizzo, A.A.; Gahm, G.A. Effectiveness of virtual reality exposure therapy for active duty soldiers in a military mental health clinic. J. Trauma. Stress 2011, 24, 93-96. [CrossRef]

43. Rizzo, A.; Cukor, J.; Gerardi, M.; Alley, S.; Reist, C.; Roy, M.; Rothbaum, B.O.; Difede, J. Virtual reality exposure for PTSD due to military combat and terrorist attacks. J. Contemp. Psychother. 2015, 45, 255-264. [CrossRef]

44. Rizzo, A.A.; Difede, J.; Rothbaum, B.O.; Johnston, S.; McLAY, R.N.; Reger, G.; Gahm, G.A.; Parsons, T.D.; Graap, K.; Pair, J. VR PTSD exposure therapy results with active duty OIF/OEF combatants. In Proceedings of the MMVR, Long Beach, CA, USA, 19-22 January 2009; pp. 277-282.

45. Rizzo, A.A.; Graap, K.; Mclay, R.N.; Perlman, K.; Rothbaum, B.O.; Reger, G.; Parsons, T.; Difede, J.; Pair, J. Virtual Iraq: Initial case reports from a VR exposure therapy application for combat-related post traumatic stress disorder. In Proceedings of the 2007 Virtual Rehabilitation, Venice, Italy, 27-29 September 2007; pp. 124-130.

46. Tworus, R.; Szymanska, S.; Ilnicki, S. A soldier suffering from PTSD, treated by controlled stress exposition using virtual reality and behavioral training. CyberPsychol. Behav. Soc. Netw. 2010, 13, 103-107. [CrossRef]

47. Wood, D.P.; Murphy, J.; Center, K.; McLay, R.; Reeves, D.; Pyne, J.; Shilling, R.; Wiederhold, B.K. Combat-related post-traumatic stress disorder: A case report using virtual reality exposure therapy with physiological monitoring. CyberPsychol. Behav. 2006, 10, 309-315. [CrossRef] 
48. Wood, D.P.; Murphy, J.A.; Center, K.B.; Russ, C.; McLay, R.N.; Reeves, D.; Pyne, J.; Shilling, R.; Hagan, J.; Wiederhold, B.K. Combat related post traumatic stress disorder: A multiple case report using virtual reality graded exposure therapy with physiological monitoring. Stud. Health Technol. Inform. 2008, 132, 556.

49. Wood, D.P.; Webb-Murphy, J.; Center, K.; McLay, R.; Koffman, R.; Johnston, S.; Spira, J.; Pyne, J.M.; Wiederhold, B.K. Combatrelated post-traumatic stress disorder: A case report using virtual reality graded exposure therapy with physiological monitoring with a female Seabee. Mil. Med. 2009, 174, 1215-1222. [CrossRef] [PubMed]

50. McLay, R.N.; McBrien, C.; Wiederhold, M.D.; Wiederhold, B.K. Exposure therapy with and without virtual reality to treat PTSD while in the combat theater: A parallel case series. CyberPsychol. Behav. Soc. Netw. 2010, 13, 37-42. [CrossRef]

51. Gamito, P.; Oliveira, J.; Morais, D.; Saraiva, T.; Rosa, P.; Leal, A.; Pacheco, J.; Ribeiro, C.; Neto, D.; Pablo, C. War PTSD: A VR pre-trial case study. Annu. Rev. CyberTher. Telemed. 2007, 5, 191-198.

52. Freedman, S.A.; Hoffman, H.G.; Garcia-Palacios, A.; Weiss, P.L.; Avitzour, S.; Josman, N. Prolonged exposure and virtual reality-enhanced imaginal exposure for PTSD following a terrorist bulldozer attack: A case study. CyberPsychol. Behav. Soc. Netw. 2010, 13, 95-101. [CrossRef]

53. Cárdenas, G.; De La Rosa, A. Using virtual reality for PTSD treatment in criminal violence victims. J. CyberTher. Rehabil. 2012, 5, 65-67.

54. Cárdenas-López, G.; De la Rosa-Gómez, A. Post-traumatic stress disorder treatment with virtual reality exposure for criminal violence: A case study in assault with violence. Int. J. Disabil. Hum. Dev. 2011, 10, 379-383. [CrossRef]

55. Beck, J.G.; Palyo, S.A.; Winer, E.H.; Schwagler, B.E.; Ang, E.J. Virtual reality exposure therapy for PTSD symptoms after a road accident: An uncontrolled case series. Behav. Ther. 2007, 38, 39-48. [CrossRef]

56. Ecrepont, A.; Haidon, C.; Girard, B.; Menelas, B.-A.J. A fully customizable truck-driving simulator for the care of people suffering from Post-Traumatic Stress Disorder. In Proceedings of the 2016 IEEE International Conference on Serious Games and Applications for Health (SeGAH), Orlando, FL, USA, 11-13 May 2016; pp. 1-8.

57. Difede, J.; Cukor, J.; Jayasinghe, N.; Patt, I.; Jedel, S.; Spielman, L.; Giosan, C.; Hoffman, H.G. Virtual reality exposure therapy for the treatment of posttraumatic stress disorder following September 11, 2001. J. Clin. Psychiatry 2007, 68, 1639-1647. [CrossRef]

58. Difede, J.; Cukor, J.; Patt, I.; Giosan, C.; Hoffman, H. The application of virtual reality to the treatment of PTSD following the WTC attack. Ann. N. Y. Acad. Sci. 2006, 1071, 500-501. [CrossRef]

59. Gahm, G.; Reger, G.; Ingram, M.V.; Reger, M.; Rizzo, A. A Multisite, Randomized Clinical Trial of Virtual Reality and Prolonged Exposure Therapy for Active Duty Soldiers with PTSD; Geneva Foundation: Tacoma, WA, USA, 2015.

60. Gamito, P.; Oliveira, J.; Rosa, P.; Morais, D.; Duarte, N.; Oliveira, S.; Saraiva, T. PTSD elderly war veterans: A clinical controlled pilot study. CyberPsychol. Behav. Soc. Netw. 2010, 13, 43-48. [CrossRef] [PubMed]

61. McLay, R.N.; Baird, A.; Webb-Murphy, J.; Deal, W.; Tran, L.; Anson, H.; Klam, W.; Johnston, S. A randomized, head-to-head study of virtual reality exposure therapy for posttraumatic stress disorder. CyberPsychol. Behav. Soc. Netw. 2017, 20, 218-224. [CrossRef]

62. Rizzo, A.; Newman, B.; Parsons, T.; Reger, G.; Holloway, K.; Gahm, G.; Rothbaum, B.; Difede, J.; McLay, R.; Johnston, S Development and clinical results from the virtual Iraq exposure therapy application for PTSD. In Proceedings of the 2009 Virtual Rehabilitation International Conference, Haifa, Israel, 29 June-2 July 2009; pp. 8-15.

63. de la Rosa Gómez, A.; López, G.C. Posttraumatic stress disorder: Efficacy of a treatment program using virtual reality for victims of criminal violence in Mexican population. Anu. Psicol. UB J. Psychol. 2012, 42, 377-391.

64. Ready, D.J.; Gerardi, R.J.; Backscheider, A.G.; Mascaro, N.; Rothbaum, B.O. Comparing virtual reality exposure therapy to present-centered therapy with 11 US Vietnam veterans with PTSD. CyberPsychol. Behav. Soc. Netw. 2010, 13, 49-54. [CrossRef]

65. Reger, G.M.; Koenen-Woods, P.; Zetocha, K.; Smolenski, D.J.; Holloway, K.M.; Rothbaum, B.O.; Difede, J.; Rizzo, A.A.; EdwardsStewart, A.; Skopp, N.A. Randomized controlled trial of prolonged exposure using imaginal exposure vs. virtual reality exposure in active duty soldiers with deployment-related posttraumatic stress disorder (PTSD). J. Consult. Clin. Psychol. 2016, 84, 946. [CrossRef] [PubMed]

66. Craske, M.G.; Treanor, M.; Conway, C.C.; Zbozinek, T.; Vervliet, B. Maximizing exposure therapy: An inhibitory learning approach. Behav. Res. Ther. 2014, 58, 10-23. [CrossRef]

67. Reger, G.M.; Gahm, G.A.; Rizzo, A.A.; Swanson, R.; Duma, S. Soldier evaluation of the virtual reality Iraq. Telemed. e-Health 2009, 15, 101-104. [CrossRef]

68. Sheridan, T.B. Musings on telepresence and virtual presence. Presence Teleoperators Virtual Environ. 1992, 1, 120-126. [CrossRef]

69. Tardif, N.; Therrien, C.-É.; Bouchard, S. Re-examining psychological mechanisms underlying virtual reality-based exposure for spider phobia. CyberPsychol. Behav. Soc. Netw. 2019, 22, 39-45. [CrossRef] [PubMed]

70. Zayapragassarazan, Z.; Kumar, S. Active learning methods. Online Submiss. 2012, 19, 3-5.

71. Prince, M. Does active learning work? A review of the research. J. Eng. Educ. 2004, 93, 223-231. [CrossRef]

72. Checa, D.; Bustillo, A. A review of immersive virtual reality serious games to enhance learning and training. Multimed. Tools Appl. 2020, 79, 5501-5527. [CrossRef]

73. Menelas, B.-A.J.; Benaoudia, R.S. Use of haptics to promote learning outcomes in serious games. Multimodal Technol. Interact. 2017, 1, 31. [CrossRef]

74. Menelas, B.-A.J.; Otis, M.J. A serious game for training balance control over different types of soil. In Proceedings of the International Conference on Serious Games Development and Applications, Bremen, Germany, 26-29 September 2012; pp. 31-42. 
75. Menelas, B.-A.J.; Otis, M.J.-D. Design of a serious game for learning vibrotactile messages. In Proceedings of the 2012 IEEE International Workshop on Haptic Audio Visual Environments and Games (HAVE 2012) Proceedings, Munich, Germany, 8-9 October 2012; pp. 124-129.

76. Kamkuimo, S.A.K.; Girard, B.; Lapointe, P.; Menelas, B.-A.J. Design and Implementation of a Serious Game to Make Construction Workers Aware of Exposure to Silica Dust in the Workplace. In Proceedings of the Joint International Conference on Serious Games, Stoke-on-Trent, UK, 19-20 November 2020; pp. 85-98.

77. Djaouti, D.; Alvarez, J.; Jessel, J.-P. Classifying serious games: The G/P/S model. In Handbook of Research on Improving Learning and Motivation through Educational Games: Multidisciplinary Approaches; IGI Global: Pennsylvanie, PA, USA, 2011 ; pp. 118-136.

78. Delmas, G.; Champagnat, R.; Augeraud, M. Plot monitoring for interactive narrative games. In Proceedings of the International Conference on Advances in Computer Entertainment Technology, Salzburg, Austria, 13-15 June 2007; pp. 17-20.

79. Hunicke, R.; Chapman, V. AI for Dynamic Difficulty Adjustment in Games, Challenges in Game Arti_cial Intelligence AAAIWorkshop. San Jose 2004, 25, 91-96.

80. Spronck, P.; Ponsen, M.; Sprinkhuizen-Kuyper, I.; Postma, E. Adaptive game AI with dynamic scripting. Mach. Learn. 2006, 63, 217-248. [CrossRef]

81. Da Silva, M.P.; Courboulay, V.; Prigent, A.; Estraillier, P. Real-time face tracking for attention aware adaptive games. In Proceedings of the International Conference on Computer Vision Systems, Santorini, Greece, 12-15 May 2008; pp. 99-108.

82. Bryant, R.A. Acute Stress Disorder: What It Is and How to Treat It; Guilford Publications: New York, NY, USA, 2016.

83. Blanchard, E.B.; Hickling, E.J.; Buckley, T.C.; Taylor, A.E.; Vollmer, A.; Loos, W.R. Psychophysiology of posttraumatic stress disorder related to motor vehicle accidents: Replication and extension. J. Consult. Clin. Psychol. 1996, 64, 742. [CrossRef]

84. Freyth, C.; Elsesser, K.; Lohrmann, T.; Sartory, G. Effects of additional prolonged exposure to psychoeducation and relaxation in acute stress disorder. J. Anxiety Disord. 2010, 24, 909-917. [CrossRef]

85. Kamkuimo, K.S.A.; Girard, B.; Menelas, B.-A.J. Dynamic Difficulty Adjustment Through real-time physiological feedback for a more adapted Virtual Reality Exposure Therapy. In Proceedings of the International Conference on Games and Learning Alliance, Laval, France, 9-10 December 2020. 